\title{
O Imaginário Feminino nas Obras de Griselda Gambaro, Isidora Aguirre e Maria Adelaide Amaral*
}

\author{
Marcos Antônio Alexandre**
}

RESUMO: O propósito deste artigo é fazer uma análise comparativa das obras dramáticas de Griselda Gambaro - La Malasangre, Isidora Aguirre - Los Papeleros e Maria Adelaide Amaral - Intensa Magia; enfatizando o papel das figuras femininas, nas obras, e a relação social, politica e cultural que estas desempenham junto à nossa sociedade. ${ }^{1}$

A imagem da mulher vem sendo modificada através dos séculos. Se pararmos para refletir perceberemos que o papel desempenhado pela mulher na sociedade, também vem sofrendo transformações. A história e a literatura sempre nos apresentaram mulheres fortes: Cleópatra, Helena de Tróia, Joana D’Arc, Safo, Pocahontas, Indira Gandhi, Escrava Anastácia, Sor Juana de la Cruz, Maria Bonita, Chica da Silva, Pagú. Estas mulheres, entre outras, subverteram a ordem daquilo que a sociedade de cada período considerava normal. Cada qual viveu segundo os seus princípios, conduzindo a sua vida de acordo com o conceito que elas próprias estabeleceram para si mesmas, não se preocupando, dessa maneira, com o que a socieda-

*Recebido para publicação em 1997.

**FALE/UFMG.

${ }^{1}$ Este trabalho nasceu na DISCIPLINA: O DISCURSO DAS MULHERES NO TEATRO LATINO-AMERICANO, ministrada pela professora Sara Rojo de la Rosa na Pós-Graduação da FALE - UFMG. 
de viria a pensar, se estavam agindo corretamente ou se estavam indo contra o cânone.

É importante que ressalvemos que os nomes citados no parágrafo anterior se referem a casos isolados de mulheres que se destacaram ao longo da história. Não obstante, o que devemos evidenciar é que a história oficial marcou a relação de subordinação da mulher ao homem, o que propiciava a sociedade patriarcal, e quando a mulher tentou inverter essa situação, houve muita revolta, sofrimento e, às vezes, até auto-anulação (como exemplo, podemos citar Sor Juana Inés de la Cruz). A mulher sempre foi considerada pela ideologia machista hegemônica o "sexo frágil", aquela que necessita da proteção dos pais, quando solteira, e do marido, se casada.

O feminismo nasceu da necessidade de desvincular o conceito de "mulher sexo frágil" da sociedade vigente, para colocar a mulher em situação de igualdade com o homem em todos os meios sociais, principalmente no trabalho. A partir do momento em que a mulher tomou conhecimento de que poderia competir com o homem em todos os aspectos - sociais, fisicos, mentais e/ou intelectuais - começou uma luta para ganhar este espaço. Isto fez com que o estudo da mulher tomasse "corpo" e deixasse de ser visto como um assunto informal. Tomar conhecimento de sua condição subordinada é o primeiro passo para a mulher chegar a esta igualdade como afirma Elena Urrutia em seu artigo "Una experiencia mexicana":

"Un análisis es feminista cuando reconoce la subordinación de la mujer en todas sus instancias y espera contribuir a la superación de la misma. En el reconocimiento de dicha subordinación hay una conciencia feminista de lo que está haciendo y para qué se hace."2(65) 
Esta consciência é encontrada nas obras dramáticas de Griselda Gambaro, Isidora Aguirre e Maria Adelaide Amaral. Apesar de que nós possamos apontar que esse nível de consciência seja distinto de uma dramaturga para outra:

- Griselda Gambaro está ciente deste seu papel de mulher e da relação que estabelece com ele na escrita; como exemplo desta forma de produção podemos citar a peça Del Sol Naciente;

- Isidora Aguirre afirma que "FAZER TEATRO É UM DURO OFÍCIO MASCULINO", entretanto o seu texto apresenta uma mensagem ideológica-politico-social, onde a mulher desempenha um papel indispensável ao desenvolvimento de sua trama dramática;

- Apesar de não sabermos que Maria Adelaide Amaral tenha, em algum momento, falado de tal consciência, podemos percebê-la nas suas obras; uma vez que ela trabalha com os relacionamentos humanos, ou seja, a autora aborda as problemáticas pessoais (familiares, amorosas) sem se preocupar em entregar soluções semi-prontas ao espectador.

Percebemos que a mulher é um dos temas centrais nas peças destas dramaturgas. $\mathrm{O}$ imaginário feminino assume diferentes funções e situações conflituosas que, de uma certa maneira, norteiam o papel que a mulher desempenha (e/ou desempenhou) na nossa sociedade.

A proposta deste artigo é fazer um levantamento e uma análise comparativa das figuras femininas nas seguintes obras:

- La Malasangre de Griselda Gambaro;

- Los Papeleros de Isidora Aguirre;

- Intensa Magia de Maria Adelaide Amaral; e, a partir destas, observar a posição da mulher perante a sociedade, seus problemas, angústias, decisões, posições ideológicas, etc. Desta 
forma, interrelacionar os pontos comuns entre a obra dramática das três autoras, os contextos históricos em que elas surgiram e tentar justificar o porquê da aproximação das dramaturgas em uma mesma linha semântica.

Gostaríamos de partir das palavras de Eugenia Brito (1987), poeta e ensaísta chilena:

"Escribir es desvelar zonas mentales encubiertas por
la cultura. Tensionar las distintas redes de sentidos
en los cuales nos encontramos codificados como
cuerpos gráficos, sociales y culturales (...). Al
escribir lo hago con todo mi cuerpo en un acto en
que ninguna de mis zonas está ausente. Escribo en
la total comparecencia de mis sentidos. Página a pá-
gina, imprimo la relación que ese cuerpo tiene con
la cultura en la que estoy inserta y de la que mi
cuerpo es producto y su interrogante". ${ }^{3}(47)$

Percebemos a presença da relação da escritura-corpo na obra das dramaturgas em análise. Cada qual impõe, respectivamente, em seu texto, o resultado de suas experiências vividas. A escritura destas autoras sai do âmbito restrito do corpo para representar o diálogo que esse "corpo" assume quando é colocado em contato com o mundo que o rodeia. A dramaturga, então, se transforma na "voz" de uma parcela da sociedade e o seu texto recebe a função de veicular estas idéias: são textos produzidos por mulheres, desde uma perspectiva de mulheres, possibilitando que se coloque em discussão o discurso "feminino" e demonstrando que esse já não está mais subjugado ao discurso masculino dominante.

A obra de Griselda Gambaro está dividida em dois momentos. No primeiro, as mulheres são apresentadas meio diluídas, como se- 
res que apenas assistem ao mundo sem dele tomar parte. Nesta linha, podemos citar as obras: El nombre, El campo e Las paredes. No segundo momento, a mulher tem a possibilidade de fazer algo para modificar o mundo à sua volta; como Antígona furiosa, Del Sol Naciente e La Malasangre, que foi estreada em 17 de agosto de 1982 no teatro Olímpia, em Buenos Aires. Esta obra se centra na figura de Dolores - filha de um pai rico e opressor e uma mãe servil. Dolores se apaixona por Rafael, um professor "jorobado" (corcunda) que o pai contrata para viver junto à família com a função de ensinar à fillha as belas letras. É prometida a Juan Pedro, um jovem rico e por quem ela só tem um sentimento: desprezo. Dolores e Rafael vivem uma conturbada história de amor, devido ao seu problema físico e à pressão que o pai e o noivo exercem sobre eles. O desfecho da trama se dá com a morte de Rafael por um empregado da casa, o que causa a revolta e a ira de Dolores.

As personagens femininas desempenham, nesta obra, um papel essencial. Dolores e a mãe representam, na obra dramática de Griselda Gambaro, duas vertentes da posição que a mulher pode vir a ocupar na sociedade, uma é o oposto da outra.

A mãe de Dolores vive à margem da figura do marido e cumpre o seu papel de "perfeita casada" com muito discernimento. Como esposa, ela não é capaz de levantar a voz para seu marido mesmo que tenha todos os motivos para fazê-lo e quando o faz é subjugada pela força:

PADRE: ¡Solo mi cara tenés que mirar, puta!

MADRE: ¡Te miro, y no me insultes!

PADRE (como si hubiera oído mal, se toca la oreja.

Mira a su alrededor, divertido): ¿Qué? Yo dicto la ley. Y los halagos. Y los insultos. Dije lo que dije, y lo puedo repetir. (Muy bajo) Puta. (...)

MADRE (se aleja hacia la puerta, se vuelve. Suavemente): Te odio. 
PADRE: ¿Qué? (Le toma el brazo, como si quisiera hacerle una caricia. Pero después de un momento, se lo tuerce) ¿Qué? Yo tampoco entiendo lo que no me gusta oír. (Le tuerce más el brazo) Te amo." (60-61)

Percebemos com esta citação que o imaginário "mulher" que surge da personagem da mãe não estimula a transformação das relações de gênero.

Dolores representa uma pessoa que sabe o que quer. A princípio, ela parece frágil, entretanto esta figura, aparentemente inocente, aos poucos se revela uma mulher segura que tem um ideal e luta para conquistá-lo. Ela apresenta uma personalidade forte e bem distinta a da mãe, de quem ela sente ao mesmo tempo pena e raiva pela posição de submissão em relação ao marido:

"DOLORES: La de papá es magnífica. (Dulcemente) Hace proyectos con las personas y las personas dicen sí.

MADRE: Esa persona es su hija.

DOLORES: O su mujer. O sus criados... Nadie puede decir no al señor de la casa. Mueve un dedo y ya está. MADRE: Ese señor es tu padre.

DOLORES: ¿Y el otro señor, mamá? ¿el que corta cabezas?"' (83-84)

A força de Dolores não se restringe a agredir verbalmente a quem está ao seu redor. Sua linguagem é carregada de ironia e ela a usa com o objetivo de não deixar que seu pai imponha sobre si o poder. Quando Dolores descobre que seu pai mandara matar Rafael, com quem ela pretendia fugir, seu ódio se volta contra tudo e todos, principalmente contra o pai que se torna o alvo maior de sua revolta. 
As metáforas conotam o texto e enfatizam os sentimentos. Por exemplo, podemos destacar a metáfora da "víbora":

"PADRE: ¿Qué criamos? ¿Una víbora? Ya te sacaremos el veneno que mastigo y trago! (..)

DOLORES(rie) ¿Qué? ¿Cómo no te das cuenta papito? Tan sabio. (Furiosa)

¡Ya nadie ordena nada! (con una voz áspera y gutural) ¡En mí y conmigo, nadie ordena nada! (...)¡Ya no tengo miedo! iSoy libre!

PADRE (furioso): ¡Silencio! ¡Nadie es libre cuando yo no quiero! (...)

DOLORES: ¡Jamás cerraré los ojos! (...) ¡ ¡Voy a mirarte siempre despierta, con tanta furia, con tanto asco! (...)

¡Te lo regalo el silencio! ¡No sé lo que haré, pero ya es bastante no tener miedo! (Ríe, estertorosa y salvaje) ¡No te esperabas ésta! ¡Tu niñita, tu tierna criatura...! (...) ¡El silencio grita! ¡Yo me callo, pero el silencio grita!" (109-110)

Outro ponto que deve ser acentuado nesta obra de Griselda Gambaro são os nomes dados ao seu texto e a sua protagonista: $L a$ Malasangre e Dolores. É interessante observarmos que os nomes, em si, apresentam uma conotação semântica muito forte e que, de uma certa forma, retratam exatamente o que a personagem viria a sofrer. Dolores sofre com a morte de seu amado e sua dor se converte numa força de rebeldia que enfrenta a repressão exercida pelo pai. La Malasangre (sangue mau) porque Dolores, enquanto personagem feminina, foge ao cânone estabelecido pela sociedade em que vive.

Esta personagem pode ser vista como uma "voz" que representa a mulher perante uma sociedade que a coloca em posição inferior 
ao homem. Dolores viria a assumir o papel em defesa de milhares de mulheres que não têm coragem de lutar para defender os seus ideais. Sua voz é o instrumento do qual ela dispõe para reivindicar seu espaço e seu reconhecimento.

A dramaturgia de Isidora Aguirre está inserida no contexto político-social chileno. A característica mais notória e constante na sua obra é a preocupação com o social. A peça Los Papeleros foi escrita em 1963 e nesta época se vivia no Chile uma eclosão de reformas que conduziriam posteriormente à abertura que possibilitou a tentativa de socialismo democrático. Esta temática é a base de sustentação da linha dramática da peça. A obra foi encenada na década de 70 e se baseia em um fato real: a existência de um "lixeiro" explorado como negócio por um dono que não tem nenhum respeito por aqueles que para ele trabalham e a rebelião de uma mulher cansada dessa exploração. Portanto, percebemos que o propósito central da obra é mostrar a condição social, a revolta desses trabalhadores e suas motivações para a luta.

Isidora Aguirre fala que se existe alguma coisa de escritura feminina na sua obra é a maneira como ela trata a mulher. A mulher tem em sua obra um papel de extrema importância, através da apresentação dos problemas que fazem parte de seu imaginário pessoal e/ ou social. Isto pode ser corroborado em Los Papeleros através da personagem La Guatona Romilia, que luta em condição de igualdade com os homens que a cercam e não se submete à força masculina só pelo fato de ser mulher:

\section{"PINTO}

Cierra el hocico o te marco pa'toda vida.

\section{ROMILIA}

Pobre de ti si me atocái'un pelo de cabeza... (Se le tira encima y le grita a Francisco y Julio que la retienen)... Ya me cansé de aguantar que el hombre 
llegue curado todas las noches y a manotones con una. Atrévete no más (..." "7 (37)

La Guatona de Romilia, além de ser a personagem principal, é a responsável pelo clímax da peça. Durante o desenvolvimento da obra, o espectador/leitor vai construindo e entendendo melhor os motivos que levam essa personagem a agir em defesa daqueles que dividem com ela a situação de precariedade e miséria. Um dos motivos que leva Romilia a lutar em prol de melhores condições de sobrevivência para si e para os seus é o fato de ter sempre em mente conseguir melhoria no seu nível de vida para poder dar a seu filho, a quem ela tinha deixado com a avó para que ele não viesse a sofrer com a pobreza que a cercava, uma vida mais digna e sem sofrimentos:

“... Bueno, ya sabís jésta es tu madre! Y ésta es la "casa" donde vive. Para que no enteraras de esto te dejé en el campo con mi taita. (...) No quiero que mi hijo pase las que yo he pasado, así es que te vas a devolver ahora mismo para San Carlos ime oís? No quiero verte guacho, vagabundeando.

(...) Vuélvete donde el abuelo, mejor. Sos muy nuevo para ganar plata. A tu edad se aprende. Mejor aguantarse estudiando para tener un buen oficio $(\ldots)^{\prime \prime}(51-52)$

Romilia fala pelo fato de ser mãe; aquela que defende sua "cria" de todos os perigos, mesmo sabendo que essa não é mais um ser frágil e inocente:

"Las mujeres somos madres y hemos aprendido a dar la pelea mejor que nadie cuando se trata de conseguir casa decente para vivir con los hijos."'(59)

? Op cit. p. 37.

${ }^{8}$ Op cit. p. $51 / 52$.

${ }^{9}$ Op cit. p. 59. 
Aqui, a personagem subverte o conceito preestabelecido pela sociedade de que cabe ao homem a responsabilidade final pela educação e bem estar dos filhos e à mulher se restringir ao espaço doméstico para atender às necessidades físicas dos filhos e esposo. Há uma desconstrução desse conceito porque Romilia não só assume para si o papel de buscar sustento e melhoria de vida para o seu filho, como também o de levar seus companheiros a reivindicarem melhores condições de trabalho e de moradia.

\section{"ROMILIA}

(...) Aquí está el acta. Consulté con abogado y dijo que estaba en regla, que firmando el Futre, por ley . tiene que entregar los sitios.

\section{PINTO}

¿Y quién lo obliga a firmar?

\section{ROMILIA}

¡Nosotros, compañeros! ¡Mientras el futre no estampe aquí su firma nos negamos a trabajarle ni un peso!(...) ¡Y vamos a la huelga! [Los mira desafiante $]^{\prime 10}(79-80)$

Isidora Aguirre demonstra sem muita sutileza o universo dos seres marginalizados e explorados pelos grandes "senhores" que detêm o poder através da coibição e da falta de consciência política daqueles que se submetem; alguns por falta de instrução, outros por não terem meios para se desvincularem do sistema político/social no qual estão inseridos.

Maria Adelaide Amaral trabalha com um micromundo dentro de um sistema que está fragmentado pelo desenvolvimento do capita- 
lismo. A época é a atual - a sociedade brasileira dos anos 90 . O seu texto abre uma porta do mundo privado para mostrar as lutas de pessoas que são reprimidas pela sociedade ou por problemas impostos e/ ou gerados por essa sociedade: trabalho, relacionamentos sociais, insatisfações pessoais e familiares.

Intensa Magia retrata a dificuldade de relacionamento de uma família de classe média "que já teve dias melhores" (fazendo uso das palavras da autora): os pais Alberto e Roma e os filhos Teresa, Zeze ${ }^{11}$ e Betinho. A família apresenta todos os conflitos possíveis. Betinho casou-se com a filha de um comerciante bem sucedido (por quem o pai sente rancor e inveja por seus negócios não terem dado certo) e raramente aparece em casa para visitar os pais. Teresa é uma mulher realizada no trabalho, que saiu de casa para se livrar do ambiente hostil em que vivia. Zeze continuou em casa e é a responsável pelo sustento da família. O pai aterroriza a todos com o seu discurso irônico e seco, não mede as palavras para se dirigir aos familiares, e com isto sempre magoa os filhos e a esposa. Ele se torna o centro das ações dramáticas da peça, uma vez que todos os momentos de clímax se desenvolvem em torno dele, que constitui o eixo destrutor do espaço familiar. O imaginário masculino é, desta maneira, apresentado negativamente.

As personagens femininas também assumem na dramaturgia de Maria Adelaide Amaral um papel indispensável ao desenvolvimento da trama. Cada personagem tem uma característica que marca a diferença entre elas, permitindo-nos perceber a importância das diferenças existentes entre as mulheres. Nesta obra nós entramos em contato com três mulheres e cada uma desempenha uma função distinta da que lhe é comum segundo os parâmetros culturais existentes em nossa sociedade. Temos a personagem de Roma, uma mulher que dedicou a sua vida para criar os filhos e servir ao marido, mesmo tendo

\footnotetext{
${ }^{11}$ Zeze - segundo texto original da dramaturga utilizado durante a realização deste artigo; onde, talvez, pudéssemos ler Zezé.
} 
a consciência de que esse convívio não é, há muito tempo, o que ela almejou para si.

"ROMA-Teus filhos são ótimos, ótimos Alberto. A gente devia levantar as mãos pro céu e agradecer a Deus os filhos que tem!" ${ }^{12}$ (13)

TERESA - E por que deixou que ele fizesse isso com você?

ROMA - Porque casamento para mim é pra vida inteira! Na alegria e na dor, na felicidade e na doença! Foi isso que eu jurei lá no altar! Pode não ser nada. para você que não tem fé que lhe valha na vida, mas é muita coisa para mim, porque eu acredito em Deus!"13 (29)

Roma representa o tipo de mulher que às vezes prefere se calar, anulando-se, para não ferir os sentimentos daqueles que vivem próximos a ela e mesmo quando não aguenta mais e levanta a voz contra a filha Teresa ou o marido, logo se arrepende do feito e tenta apaziguar a situação.

"TERESA - Você tem um pouco de inveja de mim, não tem mamãe?

ROMA - Eu só tenho inveja de quem é feliz e você é uma pobre coitada, uma mulher fácil que qualquer um leva pra cama.

TERESA - Você sempre foi insuperável na arte de me magoar...

ROMA - (Arrependida, mas com raiva) E você? Por 
que é que tinha que brigar comigo? Por que é que todo mundo tem que brigar esta noite? Eu estava tão feliz! (..)"'14 (30)

A relação com o seu marido se torna uma relação de obrigação. Mesmo quando ela tem a oportunidade de deixá-lo, não o faz. A obrigação de cumprir o papel de "esposa" fala mais alto. De alguma maneira, a dramaturga nos mostra a falsidade das representações que as mulheres assumem na sociedade:

"ROMA - (com a bandeja na mão) Quando quiser que eu sirva o jantar... (sai em direção à cozinha)."15 (61)

Podemos perceber uma certa aproximação desta personagem com a mãe de Dolores (personagem de La Malasangre de Griselda Gambaro), já que ambas representam um mesmo tipo de mulher aquela que abdica da vida própria para que sua família possa viver em "harmonia". A única diferença que há entre estas duas personagens é o tempo cronológico em que elas vivem, entretanto isto não as deixa tão distantes. A mãe de Dolores é incapaz de levantar a voz para o seu marido; Roma até o faz, mas não consegue deixá-lo, pois o seu dever de esposa (incutido em sua cabeça por costumes provenientes de uma sociedade machista e paternalista) grita mais alto dentro de si.

Nesta mesma linha de personagem, temos Zeze, que pode ser vista como um espelho meio deformado da mãe: tem 37 anos, é virgem, teve alguns namorados na vida, mas não se realizou com nenhum deles. Finalmente encontrou aquele com quem pretendia se casar - Carlos Alfredo, um ex-padre que lhe tem muito amor e respeito. Ele apresenta características distintas às do pai, por quem ela 
tem uma mescla de sentimentos: medo, amor, ódio, respeito, desprezo. Zeze, como a mãe, não conseguiu sair do ambiente no qual sua vida foi moldada; portanto, casar-se com Carlos Alfredo representa ter "liberdade" para viver sua vida sem ter que se submeter ao olhar e às palavras de ironia do pai. Afinal ela apresenta, segundo a visão da sociedade que estamos questionando, todas as características para ser uma excelente esposa: é dedicada, virgem, trabalhadora, cozinha bem, etc.

“ALBERTO - É só o que se leva desta vida... (para Zeze) E essa daí ainda insiste em virgindade. Que desperdício, meu Deus, ainda mais nesta época que ninguém liga para isso!

ZEZE - (sentida) Eu gostaria que o senhor tivesse um pouco mais de consideração por mim!" ${ }^{16}(24)$

Teresa é a personalidade mais forte da família. Enquanto mu1her, ela apresenta características opostas às da mãe e da irmã (de uma certa forma, pode ser comparada com Dolores - personagem de La Malasangre de Griselda Gambaro). É aparentemente decidida; luta pelo que quer; fala, assim como o pai, o que pensa; não sente pudor de mencionar suas relações amorosas, apesar do fato de que essas tenham sido sempre mal resolvidas. O único problema, e, talvez, o que mais lhe dói, é a relação conturbada com sua família. Toda vez que volta à sua casa se vê discutindo com a mãe pela vida que decidiu levar:

“TERESA - (para Roma) Você está sendo injusta comigo... você sabe o quanto eu gostaria que você fosse feliz... você e papai...

ROMA - E se a gente fosse feliz? Você iria ficar seis meses sem aparecer, sem dar um telefonema, sem ter uma palavra; iria nos apresentar aos seus

${ }^{16}$ Op cit. p. 24. 
amigos, se orgulhar de ser filha da gente...?

TERESA - Eu não tenho nenhum orgulho em ser filha de vocês nem vou submeter meus amigos â triste espetáculo que são as nossas reuniões de família!"17 (29)

ou com o pai, ressentida pela falta de atenção a ela dispensada. Esta mágoa, que deveria distanciá-la do pai, a faz ficar cada vez mais próxima dele:

"TERESA - (cortando) Era sempre tudo que você me negou! (chorando) Você pode não ser o único responsável por eu ser esta bosta que sou, mas sem dúvida tem uma parte muito importante na minha insegurança, na minha carência, no medo de que eu tenho de ser abandonada no melhor da festa." 18 (60)

É interessante observarmos que o realismo psicológico desta obra de Maria Adelaide Amaral retrata exatamente a relação em que algumas famílias da nossa sociedade atual vivem. Esse espaço íntimo, que a sociedade tenta esconder, é tratado por esta dramaturga de uma forma aberta e sem receios de atingir ninguém. No entanto, o que acontece é que as pessoas, ao entrarem em contato com a sua obra, seja lendo ou assistindo à peça, não conseguem fazê-lo e sair da leitura (ou do teatro) sem levantar autoquestionamentos.

Ao concluirmos a exposição das personagens femininas, presentes nas obras das autoras em anáiise, esperamos que tenha ficado claro o porquê da aproximação destas três autoras em uma mesma linha semântica. Apesar destas dramaturgas viverem em países distintos: Argentina, Chile e Brasil, respectivamente, percebemos que 
há uma proximidade nos temas que norteiam as suas obras . É impossível que nós nos deparemos com tais textos e saiamos sem fazer uma leitura transversal dos elementos presentes nos mesmos, bem como dos múltiplos sentidos com que esses elementos se relacionam com a nossa realidade sócio-cultural de latino-americanos.

Esse trabalho de aproximação e/ou oposição das personagens que desenvolvemos, nos permite, através das características de cada uma, falar com segurança que o universo da mulher: amor, maternidade, lutas, ódio, desejos, buscas, encontros, desencontros, trabaIho, dignidade (...) se encontra presente na obra das três dramaturgas.

RESUMEN: E1 propósito de este artículo es hacer un análisis comparativo de las obras dramáticas de Griselda Gambaro - $L a$ Malasangre, Isidora Aguirre - Los Papeleros y Maria Adelaide Amaral - Intensa Magia, dando énfasis al papel de las figuras femeninas, en las obras, y la relación social, política y cultural que éstas desempeñan en nuestra sociedad.

\section{RERERENCIAS BIBLIOGRÁFICAS}

AGUIRRE, Isidora. Los Papeleros. Santiago: Editorial Torsegel, 1989.

AMARAL, Maria Adelaide. Intensa Magia (original - texto ainda não editado).

BUARQUE DE HOLLANDA, Heloísa. Tendências e Impasses - O feminismo como crítica da cultura. Rio de Janeiro: Rocco, 1994.

GAMBARO, Griselda. Teatro 1 - La Malasangre. Buenos Aires: Ediciones de la Flor; 1984.

GUINSBURG, J.; COELHO NETO, J. Teixeira; CHAVES CARDOSO, Reni (organizadores). Semiologia do Teatro. São Paulo: Editora Perspectiva, 1988.

FARINA, Soledad. "Reflexiones en torno a la emergencia de una escritura femenina," In: ¿Y Nosotras Latinoamericanas? Estu- 
dos sobre Gênero e Raça. - Organizadora: Heloísa Buarque de Hollanda, São Paulo: Fundação Memorial da América Latina, 1992.

UBERSFELD, Anne. Semiótica Teatral. Madrid: Cátedra - Universidade de Murcia, 1989.

URRUTIA, Elena. "Una experiencia mexicana". In: ¿Y Nosotras Latinoamericanas? Estudo sobre Gênero e Raça- Orgnizadora: Heloísa Buarque de Hollanda, São Paulo: Fundação Memorial da América Latina, 1992. 